\title{
Promoting effects on the proliferation and metastasis of ACC tumor cell with XAGE-1b overexpression
}

\author{
BO ZHOU ${ }^{1}$, TINGXIU LI $^{2}$, YANG LIU ${ }^{3}$ and NAISHUO ZHU ${ }^{3}$ \\ ${ }^{1}$ Department of Gerontology, Zhongda Hospital Affiliated to Southeast University, Nanjing 210009; \\ ${ }^{2}$ Department of Chemotherapy, Guangxi Medical University Cancer Hospital, Nanning 530000; ${ }^{3}$ Laboratory of \\ Molecular Virology and Immunology School of Life Sciences, Fudan University, Shanghai 200433, P.R. China
}

Received July 5, 2013; Accepted August 12, 2013

DOI: $10.3892 / o r .2013 .2719$

\begin{abstract}
Adenoid cystic carcinoma is salivary gland malignancy characterized by indolent yet relentless growth that exhibits inherent resistance to surgery, chemotherapy and radiotherapy and it also expresses genes associated with well-defined carcinogenic and metastasis processes. There is no clear role established for XAGE-1b, which is a member of the cancer testis antigen family in tumorigenesis and the metastasis process of ACC. We studied and elucidated the correlation between the proliferation and metastasis of ACC and XAGE-1b. The eukaryotic vector was constructed for XAGE-1b overexpression in ACC-2 cells, which were used for studying the proliferation and migration phenotype in vivo and in vitro. RNAi technology was used to suppress the expression of XAGE-1b in the ACC-M cell line, and shRNA expression vector was also constructed and screened for interfering XAGE-1b expression applied to ACC-M cell lines. The effects on cell migration activity with XAGE-1b overexpression were determined by QCMTM 24-Well Cell Invasion Assay in vitro, and a lung metastatic model in mice. We found decreased effects on the proliferation phenotype of ACC-M cell in vivo and in vitro with XAGE-1b downregulation, and $\mathrm{XAGE}-1 \mathrm{~b}$ overexpression promoted the proliferation of ACC-2 cells in vivo and in vitro, while its overexpression promoted the transmembrane invasion of ACC-2 cells in vitro and metastasis in vivo of the nude mice. The proliferation in vitro of ACC-M cells and subcutaneous tumor growth of nude mice was inhibited by XAGE-1b interference. The ACC-2 cell line with XAGE-1b overexpression displayed more rapid proliferation and higher transmembrane and metastatic ability in vivo and in vitro, with more angiogenesis in the tumor tissues. XAGE-1b gene was able
\end{abstract}

Correspondence to: Dr Bo Zhou, Department of Gerontology, Zhongda Hospital Affiliated to Southeast University, 87 Dingjiaqiao, Nanjing, Jiangsu 210009, P.R. China

E-mail: bzhoufd@fudan.edu.cn

Key words: adenoid cystic carcinoma, XAGE-1b gene, cancer testis antigen, proliferation, transmembrane invasion to influence angiogenesis directly or indirectly, leading to tumorigenesis and metastasis of ACC.

\section{Introduction}

Carcinomas of the head and neck represent the sixth most frequent cancer worldwide, and at least $90 \%$ of them are squamous cell carcinomas (1). The overall 5-year survival rate for patients with head and neck squamous cell carcinomas (HNSCC) is among the lowest of the major cancers and has not improved dramatically in the past years $(2,3)$. Adenoid cystic carcinoma (ACC) of the head and neck is a tumor derived from the major and minor salivary glands and it accounts for around $10 \%$ of all salivary gland neoplasms, $22 \%$ of all salivary gland malignancies and $\sim 1 \%$ of all head and neck malignancies (4). ACC is an uncommon tumor and its progression is a complex process that includes malignant transformation, proliferation, invasion, and metastasis of cancer cells and a high rate of local recurrence and the delayed onset of distant hematogenous metastases, especially with a high incidence of distant metastasis (DM) to the lung (5), approximately 40-60\% of patients with ACC develop distant metastases to lungs, bone or soft tissues. Thus, distant failure remains a significant obstacle in the long-term cure of patients with ACC emphasizing the need for a better understanding of the biological factors associated with this malignancy (6). The molecular mechanism of the metastasis development is poorly understood, largely because the metastasis is a complex process involving several distinct steps such as escape from primary tumor, dissemination through the circulation, lodgment in small vessels at distinct sites, penetration of the vessel wall and growth in the new site as a secondary tumor (7). Most deaths from salivary ACC are caused by lung metastases that are resistant to conventional therapy. Therefore, the development of new treatment strategies for the primary tumor and for metastatic lesions remains a challenge. Although reasons for the invasiveness and aggressive metastatic dissemination of ACCs remain unclear, there is some research suggesting that angiogenesis may be a possible mechanism involved (8).

Cancer/testis antigens (CTAs) comprise the largest family of tumor antigens, of which $>40$ have now been identified, are encoded by genes that are normally expressed only in 
the human germ line, but are also expressed in various tumor types, including melanoma, and carcinomas of the bladder, lung and liver. CTAs are also being evaluated for their role in oncogenesis - recapitulation of portions of the germline geneexpression programme might contribute characteristic features to the neoplastic phenotype, including immortality (9). In recent years several CTAs, includingMAGE-A1, MAGE-A3, NY-ESO-1, SSX2 and XAGE-1b, were found in lung tumors (10-13), making it possible to apply CTA based immunotherapy to the treatment of lung cancer $(14,15)$. XAGE-1 was identified originally as a PAGE/GAGE related gene on the $\mathrm{X}$ chromosome by expressed sequence tag (EST) analysis (16). Studies of XAGE-1 expression revealed that the gene is a CTA and it has been shown since to be expressed in metastatic melanoma, Ewing's sarcoma and some epithelial tumors, including those of the breast and lung (17-19). Among the four splice variants of XAGE-1 (XAGE-1a, b, c and d), XAGE-1b is regarded as the most immunogenic, capable of eliciting cellular and humoral immune responses. It is also highly expressed in lung adenocarcinoma; thus, XAGE-1b is one of the most promising targets for lung adenocarcinoma immunotherapy $(20,21)$. There is no report of research on the specific tumor marker or the gene connected with migration of $\mathrm{ACC}$, but there are some IHC results which showed some correlation between protein kinase K, laminin, fibronectin, keratin14, S-100 protein, P16 and P27 and the pathologic stage or migration of ACC (3). The investigation focusing on the migration of ACC based on the molecular level have begun $(4,6)$, but there are no studies on the mechanism on its migration at more high tendency so far to our knowledge.

The eukaryotic overexpression XAGE-1b vector was constructed, and the screened stably expressed cells were used for the study of proliferation and migration phenotype in vivo and in vitro. We constructed and screened the shRNA expression vector for interfering with XAGE-1b expression in ACC-M cells. The proliferation phenotype of ACC-M cells was observed with XAGE-1b downregulation, and found both in vivo and in vitro. The ACC-M cell proliferation in vitro and subcutaneous tumors of nude mice were inhibited through interfering XAGE-1b gene expression, ACC-2 cells with overexpression of XAGE-1b showed more rapid proliferation and transmembrane and migration in vivo and in vitro, with more angiogenesis. All the above results indicated that XAGE-1b influenced the angiogenesis directly or indirectly, and it led to migration. Therefore, the correlation between XAGE-1b expression and lung metastases of $\mathrm{ACC}$ was proven. The results may contribute to treatment of ACC focusing on XAGE-1b as a drug target.

\section{Materials and methods}

Design and synthesis of the primers. Eukaryotic expression vector of $\mathrm{pE}-\mathrm{Xb}$ which only expressed XAGE-1b protein was constructed from pEGFP-N1, and pEGFP-XP-GFP constructed from pEGFP-N1 is a fusion protein expression vector combining with GFP. All the primer sequences are shown in Table I. The shRNA expression vector especially interfering with XAGE-1b expression was designed and constructed to pGCsi-U6/Neo/RFP. All the single oligo nucleotide sequences are shown in Table II. The primers used for detecting XAGE-1b and GAPDH expression by RT-PCR are shown in Table III.

Construction of recombinant plasmids. To acquire cDNA of XAGE-1b from ACC-M cells and to amplify the fragments with the primers of GN-1B-F and GN-1B-R, the fragments were inserted into pEGFP-N1 plasmid $\mathrm{pE}-\mathrm{Xb}$ expression vector without GFP fusion. XAGE-1b vectors with GFP fusion were constructed with the primers, including XAGE1b, GN-1B-F and GN-1B-R (G), named pEGFP-Xb-GFP. Negative control vector of pEGFP-N1 was named pE-Negative. The shRNA for specially interfering with XAGE-1b was designed and synthesized and constructed into pGCsi-U6/ Neo/RFP vector by Jikai (Shanghai, China). There are three interfering vectors, including Sh-a, Sh-b and Sh-c, and the positive control sequence named pG-Positive is designed specially for interfering with GFP expression, the negative control sequence (anything except for sequences against any human gene), was named pG-Negative.

Animals, cell lines and cultures. The nude mice (BALB/c $\mathrm{nu} / \mathrm{nu}$ ) were purchased from the Animal center of Shanghai, and cultivated in the animal experimental center of the Second Military Medical University (Shanghai, China). The human salivary ACC-2, ACC-M, SPC-A1 and 293T cells used in the study were obtained from American Type Culture Collection (ATCC, Manassas, VA, USA). ACC-2, ACC-M, SPC-A1 cells were cultured in RPMI-1640 from Gibco (Langley, OK, USA) supplemented with $10 \%$ fetal bovine serum (FBS) from Sigma (St. Louis, MO, USA) at $37^{\circ} \mathrm{C}$ in a humidified atmosphere of $5 \% \mathrm{CO}_{2}$ in air. 293T cells were cultured in DMEM from Gibco (Carlsbad, CA, USA) supplemented with $10 \%$ FBS. All chemicals needed for cell culture were purchased from Gibco. The effective fragments of RNA interfering were chosen based on screening RNA interfering exogenous expression in $293 \mathrm{~T}$ cells and SPC-A1 cells.

RNA extraction, cDNA synthesis, and RT-PCR. Reverse transcription-PCR. Total RNA isolated from above culture cells was prepared with TRIzol (Invitrogen, Carlsbad, CA, USA) according to the manufacturer's instructions. RNA quantification was done using spectrophotometry. Semi-quantitative RT-PCR analysis for shRNA interfering expression and the internal control GAPDH was carried out using ABI PE9600 PCR System. The PCR products were electrophoresed on $2 \%$ agarose gel and stained with ethidium bromide (Pierce, Rockford, IL, USA). Quantitative reverse transcription PCR analysis was carried out to understand the efficacy of the shRNA interfering expression.

Western blot analysis. ACC-2 cells were collected into $1.5 \mathrm{ml}$ Eppendorf tubes on ice, centrifuged at $800 \mathrm{rpm}$ for $5 \mathrm{~min}$ at $4^{\circ} \mathrm{C}$, resuspended in $100 \mu \mathrm{l}$ cell lysis buffer containing proteinase inhibitor, and incubated on ice for half an hour. The lysates were centrifuged at $14000 \mathrm{rpm}$ for $30 \mathrm{~min}$ at $4^{\circ} \mathrm{C}$, the supernatants were collected and stored at $-70^{\circ} \mathrm{C}$ for electrophoresis. The concentration of protein sample was determined by the Lowry method. Proteins in conditioned media were separated by electrophoresis on $15 \%$ SDS-PAGE gels and transferred electrophoretically onto nitrocellulose 
Table I. The primers of XAGE-1b expression vector.

\begin{tabular}{lrlrc}
\hline Construction of vector & Primer & \multicolumn{1}{c}{ Primer sequences } & Plasm & Restriction sites \\
\hline pE-Xb & GN-1B-F & 5'-TCGACTCGAGATGGAGA & pEGFP-N1 & XhoI \\
& & GCCCCAAAAAGAAGA 3' & & EcoRI \\
& GN-1B-R & 5'-CGCGGATCCTCATTAAACT & & XhoI \\
& & TGTGGTTCTCTTCAC-3' & & EcoRI \\
pEGFP-Xb-GFP & GN-1B-F & 5'-TCGACTCGAGATGGAGA & pEGFP-N1 & \\
& & GCCCCAAAAAGAAGA-3' & & \\
& GN-1B-R(G) & 5'-CCGGAATTCGAACTTG & & \\
& & TGGTTGCTCTTCAC-3' & & \\
\hline
\end{tabular}

Table II. Targeting sequences of XAGE-1b interfering vector.

\begin{tabular}{llccc}
\hline Plasmid & $\begin{array}{c}\text { Construction } \\
\text { of vector }\end{array}$ & $\begin{array}{c}\text { Oligo sequences of } \\
\text { targeting RNAi }\end{array}$ & $\begin{array}{c}\text { Sequences of } \\
\text { palindromic structure }\end{array}$ & $\begin{array}{c}\text { Location of the } \\
\text { targeting transcription }\end{array}$ \\
\hline PGC & Sh-a & 5'-AGAACCAGCAGCTGAAAGT-3' & TTCAAGAGA & $144-163$ \\
& Sh-b & 5'-GCTGCATCAGTCAAACACC-3' & TTCAAGAGA & $249-268$ \\
& Sh-c & 5'-AGCTGAAACAACGCAAGCT-3' & TTCAAGAGA & $380-399$ \\
& pG-Negative & 5'-GGCTGCGCATTGCCATAAA-3' & TTCAAGAGA & - \\
\hline
\end{tabular}

Table III. The primer sequences for semi-quantative PCR detection.

\begin{tabular}{llc}
\hline Gene & Primer & \multicolumn{1}{c}{ Primer sequences } \\
\hline GAPDH & G real-F & 5'-AGAAGGCTGGGGCTCATTTG-3' \\
& G real-R & 5'-AGGGGCCATCCACAGTCTTC-3' \\
XAGE-1b & 1b-S & 5'-TACTGAGACACGGCGGAC-3' \\
& 1b-AS & 5'-TTCCATGTCGCGCACTG-3' \\
\hline
\end{tabular}

membranes. After being blocked for $2 \mathrm{~h}$ with $5 \%$ skim milk, blots were incubated with 1:1,000 diluted sheep anti-human antibody XAGE-1b and 1:3000 diluted antibody GAPDH at room temperature overnight. After four washes with PBST, the membrane was separately incubated with rabbit antisheep antibody at a dilution of 1:2,000 and sheep anti-mouse antibody GAPDH at a dilution of 1:4,000 for $1 \mathrm{~h}$ and $45 \mathrm{~min}$, respectively. Finally, the protein bands were visualized with an ECL kit. Quantitative analysis of the blots was performed with an imaging densitometer and GAPDH as the control. GAPDH served as an internal control for total cDNA content.

Cell proliferation assay. MTT assay was used for detecting cell proliferation. The stably expressing cell lines of ACC-2 and ACC-M were cultured to logarithmic growth phase and synchronized with serum-free medium for $24 \mathrm{~h}$. All the cells were inoculated on a 96-well plate and measured four times every $24 \mathrm{~h}$ continuously. MTT (10 $\mu \mathrm{l}$ ) (Sigma) was added into the plate, $4 \mathrm{~h}$ later, $100 \mu \mathrm{l}$ DMSO (Sigma) was added after emptying the cell plate and the $\mathrm{OD}_{570}$ values were measured with the SpectraMax M5 (Molecular Devices Corp., Concord, Ontario, Canada). Then the proliferation curve was drawn.

Cloning of cell lines. The stable expression cell lines of ACC-2 and ACC-M were cultured to logarithmic growth phase and synchronized with serum-free medium for $24 \mathrm{~h}$. The cells were inoculated onto a 6 -well plate $\sim 500$ cells per well with three repeat wells, and cultured with the G418-free medium. After 14 days, the medium was removed and washed two times with PBS. Crystal violet $(500 \mu \mathrm{l})$ was added into the well and stained for $5 \mathrm{~min}$, then the dye was removed and washed two times again with PBS.

Transmembrane experiment in vitro. The transmembrane experiment in vitro with ACC-2 cell line was carried out according to the manufacturer's instructions of the QCMTM 24-Well Cell Invasion Assay kit (Chemicon, Billerica, MA, USA). The transmembrane rate was calculated according to the experimental results.

Analysis of subcutaneous tumor growth in vivo of nude mice and lung metastasis. Experimental groups, and amount of cells are list in Table IV. The nude mice were divided into three groups. Each cell line was cultured in a bottle as $2 \times 10^{6}$ cells, and the activity of cells was measured by staining with $0.2 \%$ Trypan Blue. The cells were synchronized by replacing with fresh serum-free and double-anti medium overnight before the inoculation. Cells were digested with $0.25 \%$ trypsin and counted using an automated counter before centrifugation. The concentration was adjusted to $1 \times 10^{7} \mathrm{cell} /$ $\mathrm{ml}$ by serum-free medium and prepared for injection. Cell suspension $(100 \mu \mathrm{l})$ as $1 \times 10^{6}$ cells was injected s.c. into the back or the tail vein of 4- to 6-week-old female BALB/C nu/ 
Table IV. The groups of subcutaneous tumorigenesis of the nude mice in vivo.

\begin{tabular}{llcc}
\hline Groups & \multicolumn{1}{c}{ Cell lines } & Number of the nude mice & Amount of cell \\
\hline ACC-2 cell subcutaneous & ACC-2-Xb-19 & 5 & $1 \times 10^{6}$ \\
& ACC-2-Xb-M & 5 & $1 \times 10^{6}$ \\
& ACC-2-pE-Negative & 5 & $1 \times 10^{6}$ \\
& ACC-2 & 5 & $1 \times 10^{6}$ \\
ACC-M cell subcutaneous & ACC-M-pG-Sh-a & 4 & $1 \times 10^{6}$ \\
& ACC-M-pG-Negative & 4 & $1 \times 10^{6}$ \\
ACC-2 cell tail vein & ACC-M & 4 & $1 \times 10^{6}$ \\
& ACC-2-Xb-19 & 6 & $1 \times 10^{6}$ \\
& ACC-2-Xb-M & 6 & $1 \times 10^{6}$ \\
& ACC-2-pE-Negative & 6 & $1 \times 10^{6}$ \\
& ACC-2 & 6 & $1 \times 10^{6}$ \\
\hline
\end{tabular}

A
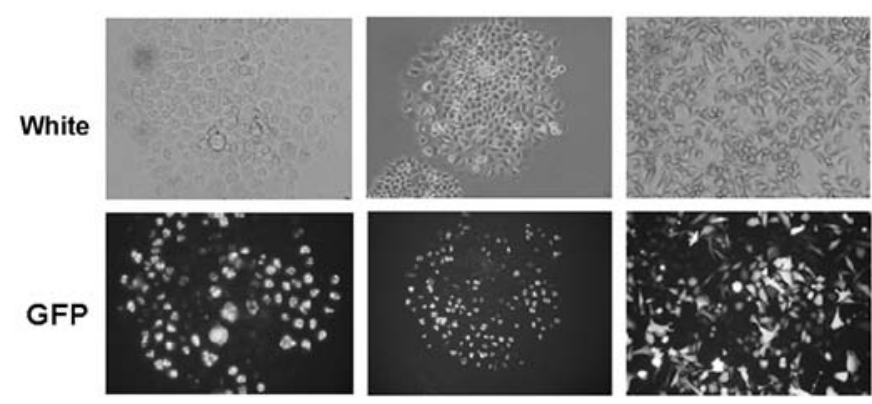

Figure 1. The stable cells screened after the transfection applying with pEGFP-Xb-GFP and pE-Negative vectors. (A and B) Two stable XAGE1b-GFP fusion protein expression clones with G418 screening and its distribution in the nucleus. (C) The stable clone was named ACC-2-pE-N after the $\mathrm{pE}-$ Negative vector transfection and with the positive rate of $93 \%$.

nu nude mice. The condition of tumor and tumorigenesis time was observed and recorded, the long and short diameter of tumor were measured after inoculation every three days during the first two weeks and every other day during the third to the forth week. The formula for calculating the tumor is $1 / 2 \mathrm{ab}^{2}$, a being the maximum diameter and $b$ the minimum diameter of tumor. The nude mice were photographed and the growth curve was drawn. The mice were sacrificed 4 weeks later and photographed again, and weighed, and all were dissected, and tumor tissues were removed. The tumor and lung tissues with formalin-fixed and paraffin-embedded were preserved for identification of RNA and DNA.

$H \& E$ and IHC staining of the tumor lung tissue, and the microvessel density. H\&E staining: All the tumor tissues were fixed in formalin and embedded in paraffin. Sections (5 $\mu \mathrm{m}$ thick) were obtained and used for H\&E staining. Each section was photographed at x200 magnification. IHC staining: Antigen retrieval was performed on tumor tissue of the XAGE-1b subcutaneous expression group with formalinfixed and paraffin-embedded, and stained with the antibody
XAGE-1. Follow-up staining of the sections were performed by the Ultra Sensitive S-P kit Goat system and photographed at x200 and x400 magnification, respectively.

Counting of the microvessel density of the tumor: the tumor tissue slides were stained by IHC with antibody CD31 (Zhongshan Co., Beijing, China), and there are specific red-brown particles precipitated on the surface of vascular endothelial cells. Five different levels were stained, and two areas at $\times 200$ magnification were randomly selected and photographed. The number of the stained microvessels and the average number of the microvessels in five levels represent the microvessel density of tumor tissue.

Statistical analysis. Data are presented as the means \pm SD. Multiple group comparisons were analyzed by one-way ANOVA after Bonferroni's correction. Non-parametric data between two groups was computed by Chi-square test or Fisher Exact test. The difference of two groups was determined by Student's t-test. A P-value of $<0.05$ was considered statistically significant.

\section{Results}

Promotion effects on the proliferation of ACC-2 cells with $X A G E-1 b$ overexpression in vivo and in vitro. The expression vector, including $\mathrm{pE}-\mathrm{Xb}$ and $\mathrm{pEGFP-Xb-GFP}$ of XAGE-1b, and the empty vector $\mathrm{pE}-\mathrm{Neg}$ ative were transfected into ACC- 2 cells. There are two monoclones after transfection with pEGFP-Xb-GFP which expressed the fusion protein of GFP and XAGE-1b. The green fluorescence focused in the nucleus with the distribution of small points, and the monoclone ACC-2-pE-Negative, obtained from ACC-2 cells transfected with the empty vector as the negative control. The monoclonal cell lines express green fluorescence protein stably and the positive rate reaches $93 \%$ (Fig. 1).

The stable cell clones were obtained by G418 screening after $\mathrm{pE}-\mathrm{Xb}$ transfection. The nineteenth stable expression clone showed the maximum value based on XAGE-1b expression by western blot assay and was named ACC-2-Xb-19 (Fig. 2A, upper image). The residual G418-resistant cells 
A

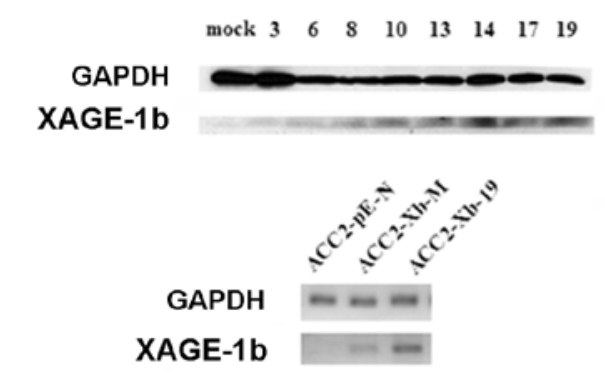

C

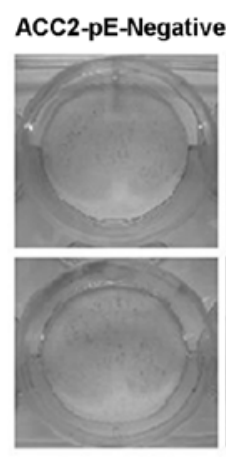

E

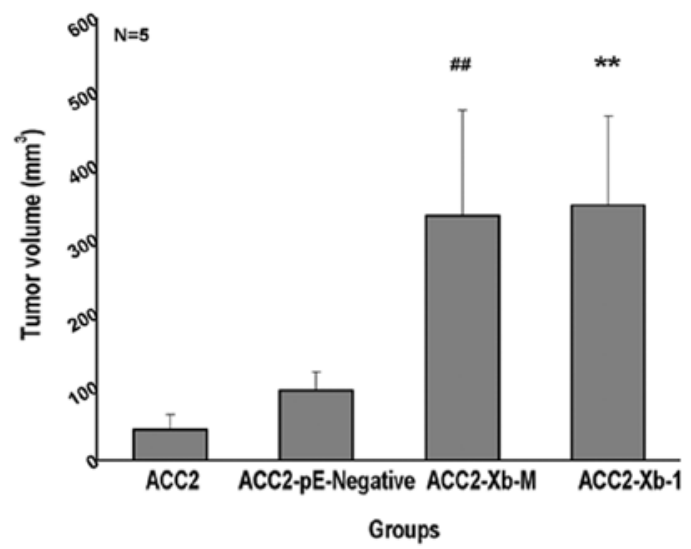

B

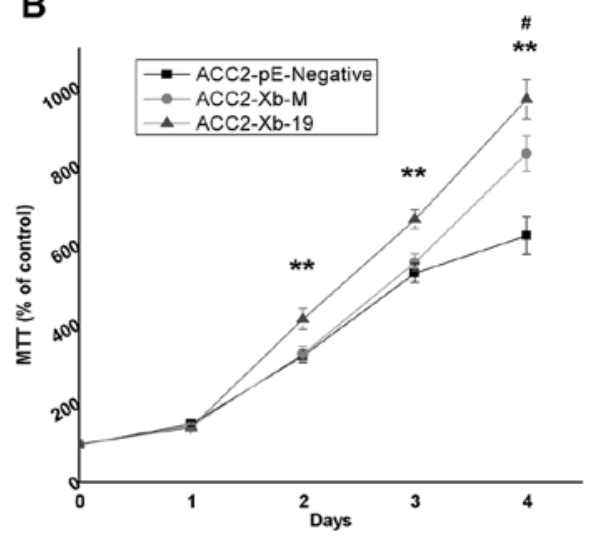

D

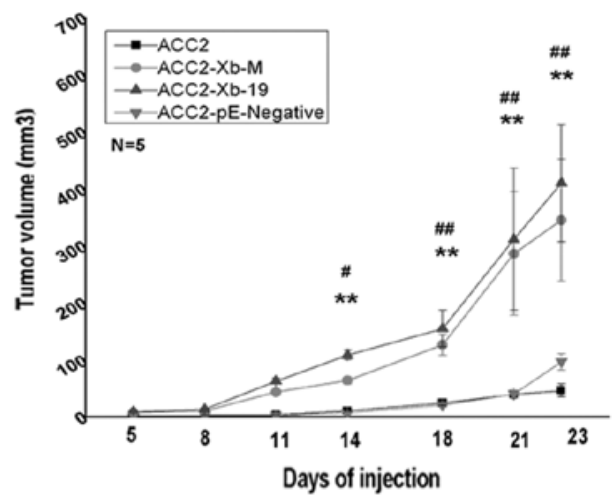

$\mathbf{F}$

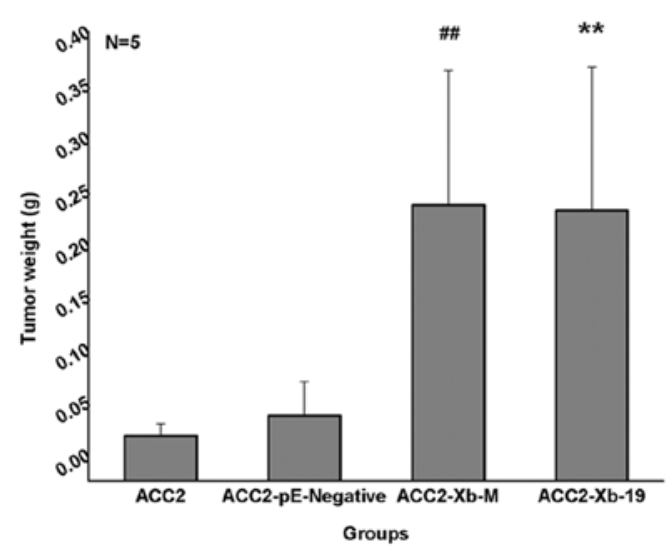

Figure 2. The effect on ACC-2 cell proliferation in vitro and the subcutaneous proliferation in vivo of the nude mice with XAGE-1b overexpression. (A) The results of western blotting and RT-PCR assay. The upper image is the amounts of XAGE-lb protein expression with pE-Xb and pE-Negative plasmid transfection, respectively. Mock named ACC2-pE-N represents the stable cells after empty vector transfection. The number 3, 6, 8, 10, 13, 14, 17 and 19 represent the cells with the stable XAGE-1b expression, respectively. The number 19 clone named ACC2-Xb-19 showed the highest expression level. GAPDH is the control of the total protein. The lower image is RNA semi-quantitative result of ACC2-pE-N, ACC2-Xb-19 and ACC2-Xb-M with G418 resistance after screening. (B) The results of MTT originated from three independent experiments and three wells each time. (C) The results of the different clones. (D) The tumor growth curves. Tumor volume is calculated according to the formula $1 / 2 \mathrm{ab}^{2}$, a is the maximum diameter and $\mathrm{b}$ is the minimum diameter (mean $\pm \mathrm{SD}$, $\mathrm{n}=5$ ). (E) The comparison of the tumor volume (mean $\pm \mathrm{SD}, \mathrm{n}=5$ ). (F) The comparison of the tumor weight (mean $\pm \mathrm{SD}, \mathrm{n}=5$ ). *Represents the comparison between ACC2-Xb-19 and ACC2-pE-N. "Represents the comparison between ACC2-Xb-M and ACC2-pE-N, ${ }^{*} \#, \mathrm{P}<0.05,{ }^{* *} \# \#, \mathrm{P}<0.01$.

without cloning were continuously cultured and named ACC-2$\mathrm{Xb}-\mathrm{M}$. XAGE-1b expression in the cell lines is different by the semi-quantitative RT-PCT assay, and XAGE-1b expression in ACC-2-Xb-19 is maximal among the cell lines, XAGE-1b expression in ACC-2-pE-Negative is minimal (Fig. 2A, lower image), and the expression in $\mathrm{ACC}-2-\mathrm{Xb}-\mathrm{M}$ is in between the two groups. The above three cell lines and ACC- 2 cells were applied for studying the proliferation in vivo and in vitro. Based on the MTT assay, the number of ACC-2-Xb-19 cells increased greatly compared with ACC-2-pE-Negative after two days of culture ( $<<0.01$, Fig. $2 \mathrm{~B}$ ). The number of mixed expression ACC-2-Xb-M cells showed the difference in the negative control at the beginning of the fourth day $(\mathrm{p}<0.05$, Fig. 2B). There are differences among the three cell lines of the cloning number, and the number of ACC-2-Xb-19 is almost two times that of the negative control (Fig. 2C).

The effects of XAGE-1b on the subcutaneous tumor in ACC- 2 cells were detected in vivo of the nude mice. All 
A

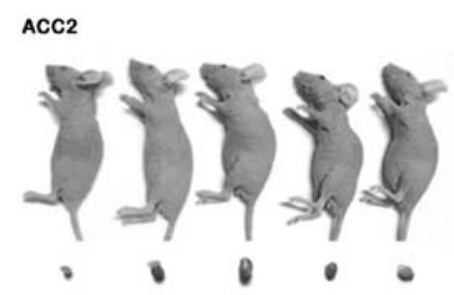

ACC2-pE-Negative

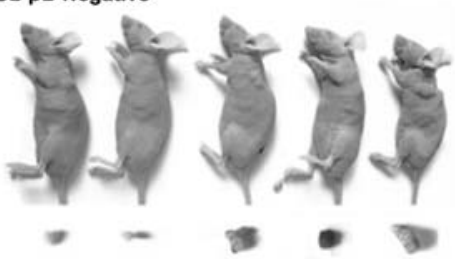

ACC2-Xb-19
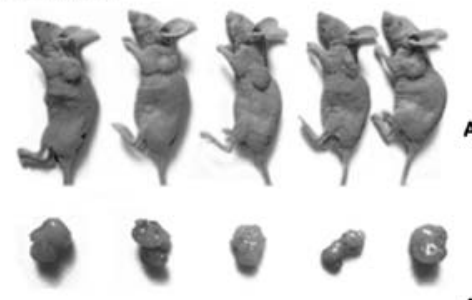

ACC2-Xb-M

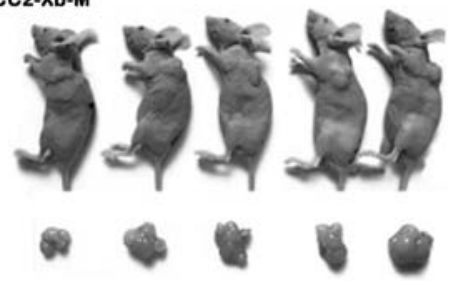

D

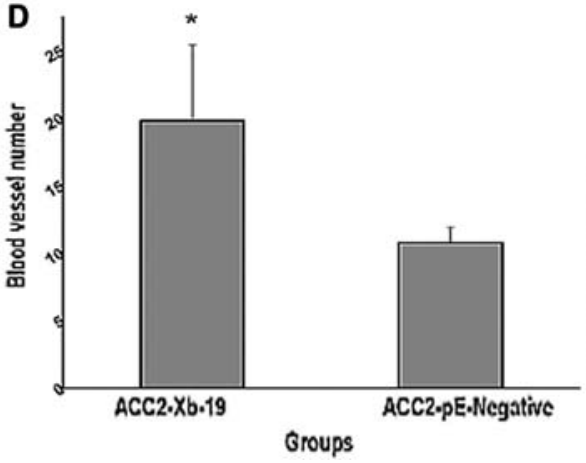

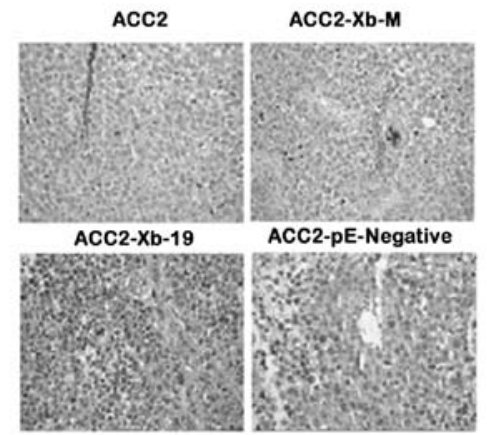

C

Positive Negative

Acc2-Xb-M

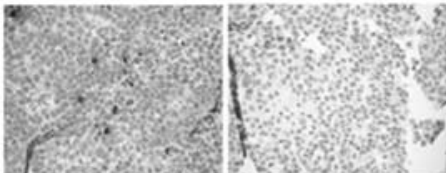

.colitatio
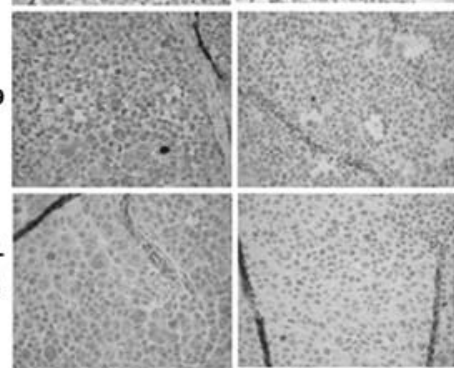

E

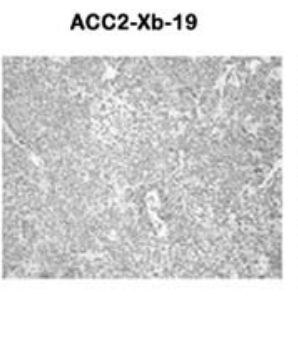

ACC2-pE-Negative

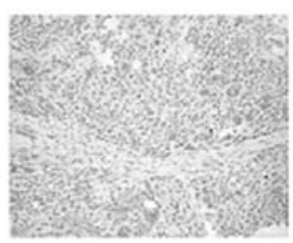

Figure 3. The subcutaneous tumor growth of ACC-2 cells with XAGE-1b overexpression in the nude mice. (A) Subcutaneous tumor growth in different groups, including ACC2, ACC2-pE-N, ACC2-Xb-19 and ACC2-Xb-M (n=5), and the scale bar characterizing the tumor size as the scale of $1 \mathrm{~cm}$ in the lower right corner. (B) H\&E staining of tumors (x200). (C) IHC staining of XAGE-1b protein in the tumor. Left, positive staining with XAGE-1b antibody; right, negative control staining with the second XAGE-1b antibody. (D) Subcutaneous tumor vascularization in ACC2-pE-N cells. The blood vessel number is the average value from two fields at x 200 magnification of one selected from five random sample slices and with the significant difference between the two groups. $\left({ }^{*} \mathrm{P}<0.05\right)$. (E) A typical stained map of blood vessels from the tumor tissues in ACC2-Xb-19 and ACC2-pE-N group, respectively.

cells with the counts of $1 \times 10^{6}$, including ACC-2-Xb-19, ACC-2-Xb-M, ACC-2-pE-Negative and ACC-2, were injected s.c. into the left back of mice, and the mice were observed and measured once every three days. The tumors formed in $\mathrm{ACC}-2-\mathrm{Xb}-19$ and $\mathrm{ACC}-2-\mathrm{Xb}-\mathrm{M}$ groups grew rapidly compared with ACC-2-pE-Negative and ACC-2 at the beginning of the fourteenth day, and the results showed the difference among the cell lines (Fig. 2D). We found that the average tumor volume of ACC-2-Xb-19, and ACC-2-
$\mathrm{Xb}-\mathrm{M}$, was 4-8 times higher than the other two groups, the ACC-2-pE-Negative and ACC-2 groups (Fig. 2E), and the tumors weight was $\sim 7-11$ times that of the control (Fig. 2F). The mice were sacrificed three or four weeks later and the tumor tissues were weighed with record and photographed in detail (Fig. 3A). H\&E staining of tumor tissues confirmed $t$ the typical histological features of ACC (Fig. 3B). XAGE-1b protein with IHC staining 2 was expressed much stronger in ACC-2-Xb-19 and ACC-2-Xb-M cells (Fig. 3C). The average 

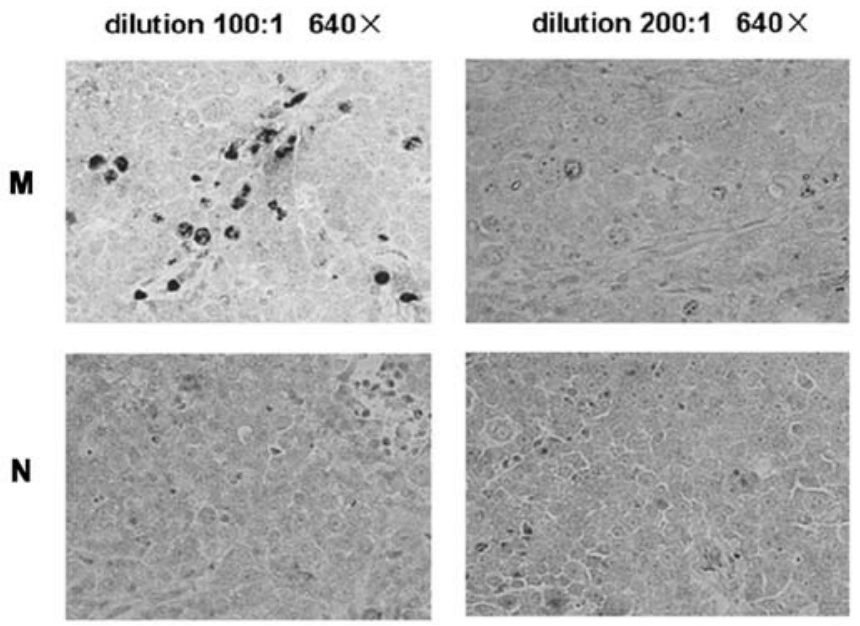

Figure 4. IHC staining of XAGE-1 protein in tumorigenesis originated from ACC-pE-M cells. Primary antibody diluted 100 times and 200 times respectively. $\mathrm{M}$, tumorigenesis of $\mathrm{ACC}-\mathrm{pE}-\mathrm{dM}$ cells; $\mathrm{N}$, the control group of tumorigenesis of ACC-pE-N cells.

MVD of a tumor is $19.8 \pm 5.57 /$ field and it is higher than the control, 10.75 $\pm 1.15 /$ field ( $<<0.05$, Fig. 3D and E). At x640 magnification it is very clear that XAGE-1b staining focused in the nucleus. We detected the CD31 staining and calculated the microvessel density (MVD) of tumor tissues in each group to verify the correlation of enhancement between tumorigenesis and angiogenesis (Fig. 4).

Promotion effects on the transmembrane invasion in vitro and metastasis in vivo of nude mice with XAGE-1b overexpression. We detected the transmembrane ability of ACC-2 cells with XAGE-1b protein expression and other cells by a kit simulating transendothelium stroma to verify the hypothesis of tumor metastasis promotion of ACC with XAGE-1b overexpression. The standard curve was drawn to reflect the correlation between the amounts of transmembrane cells and the fluorescence intensity (Fig. 5A). Cells of four groups were inoculated in three wells, respectively. The amount of transmembrane cells in ACC-2-Xb-19 is three times that of ACC-2 (p $<0.01$, Fig. 5B) and the amounts of transmembrane cells in ACC-2-Xb-M is $\sim 1.5$ times that of ACC-2 ( $<<0.01$, Fig. 5B). There is no significant difference between ACC-2pE-Negative and ACC-2. The data showed that XAGE- $1 \mathrm{~b}$ overexpression promoted the invasion ability of ACC-2 cells in vitro.

We established the nude mouse model of lung mestastasis to study the ability of invasion and metastasis promoted by XAGE-1b in vivo and tested the hypothesis applying the metastasis rate analysis. All cells, including ACC-2-Xb-19,
A

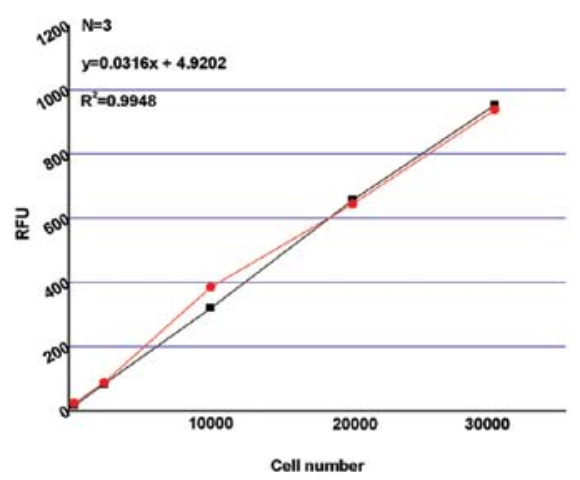

B

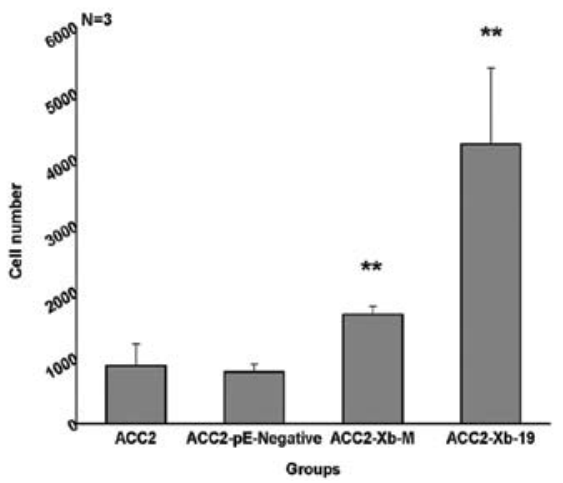

C

\section{ACC2-pE-Negative ACC2-Xb-M ACC2-Xb-19}
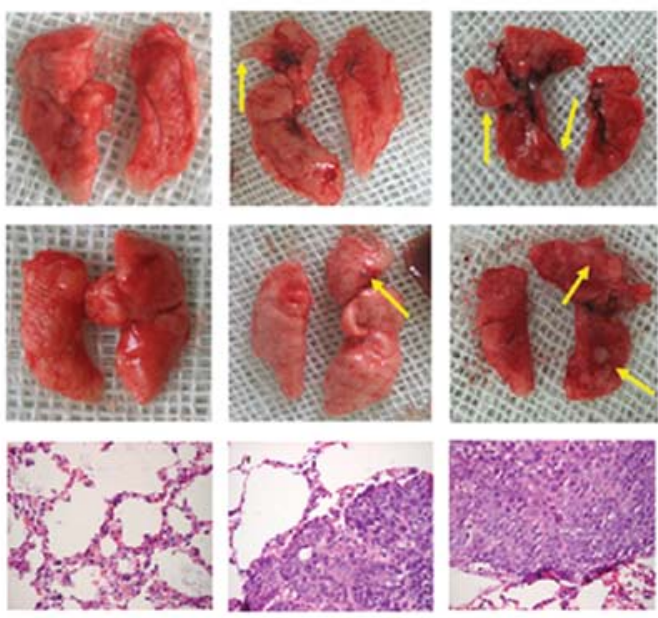

Positive
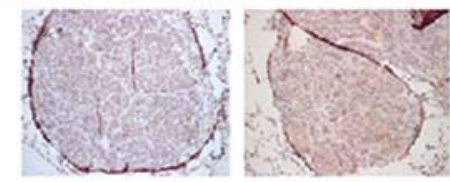

Negative
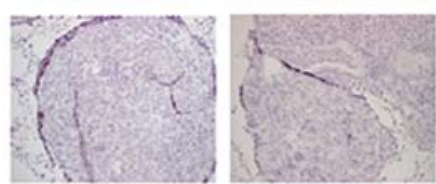

Figure 5. The effect on the transmembrane ability of ACC-2 cells and the lung migration of the nude mice with XAGE-1b overexpression. (A) The standard curve representing the correlation between the transmembrane cell number and relative fluorescence units (RFU). (B) The comparison of the transmembrane cells calculated from the standard curve $\left.{ }^{* *} \mathrm{P}<0.01\right)$. (C) The evident lung tumor nodules of the nude mice in ACC2-Xb-19 and ACC2-Xb-M group are shown in the first and second line, no tumor nodules were observed in the control group. H\&E staining of tumor tissues are shown in the third line. The tumor tissues show the typical characteristics of ACC in ACC2-Xb-19 and ACC2-Xb-M group, but no tumor nodules in the negative group. IHC staining of XAGE-1b protein with lung metastases is shown in the fourth line. IHC staining of the negative control is shown in the last line. 

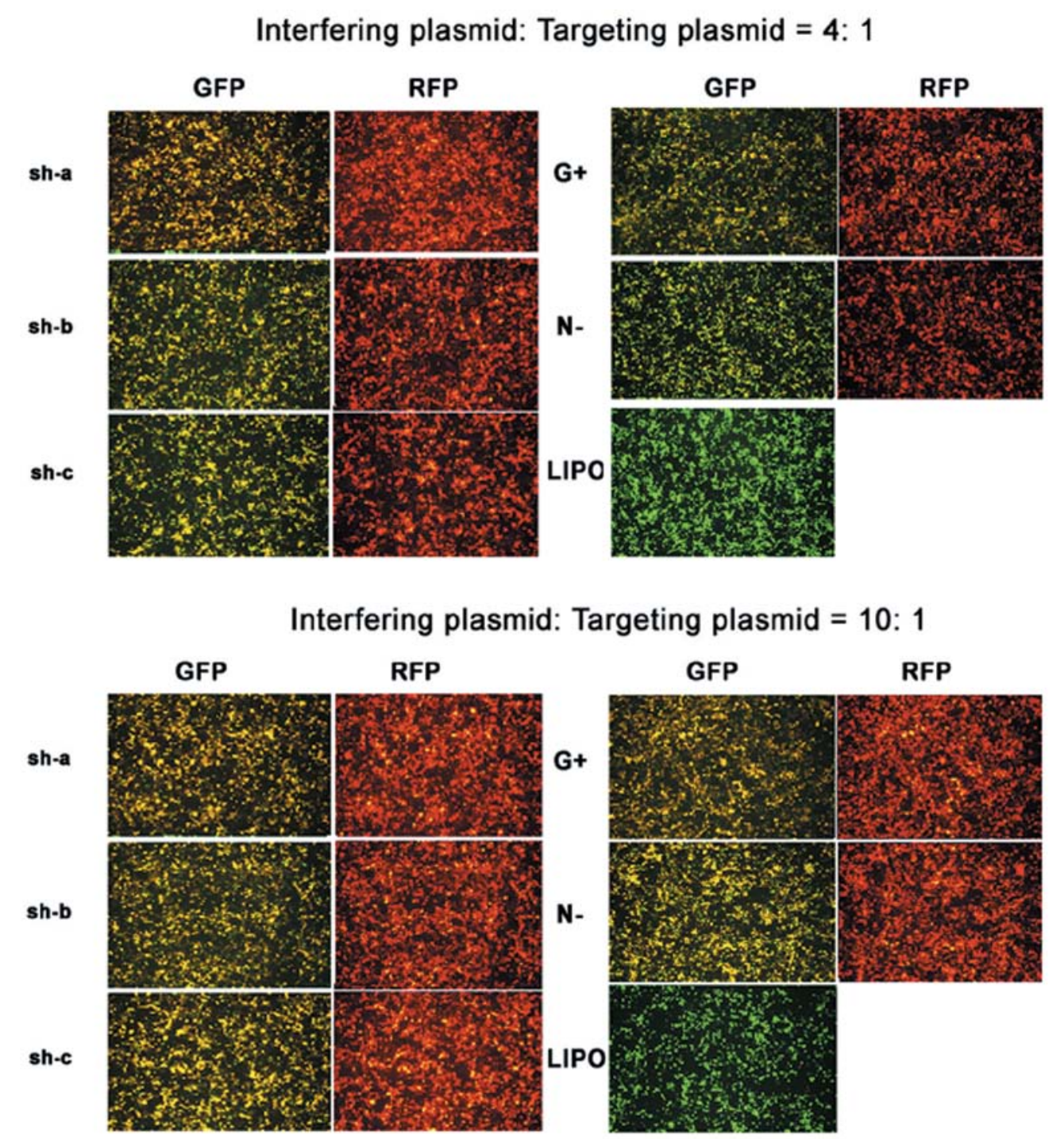

Figure 6. The effects of the exogenous interference of shRNA expression vector against the XAGE-1b gene.

ACC-2-Xb-M and ACC-2-pE-Negative, were injected into the tail vein of the nude mice. The nude mice were sacrificed 56 days later, and the lungs were dissected. The evident tumor nodules were observed on the lung of two mice in ACC-2-Xb-19 and one in ACC-2-Xb-M, but there are no nodules in the control (Fig. 5C, the first and second line). The average metastasis rate was calculated according to the PCR results. The lung migration based on the molecular level could be detected whether there was any visualized tumor nodules or not in ACC-2-Xb-19 and $\mathrm{ACC}-2-\mathrm{Xb}-\mathrm{M}$, and the average metastasis rate was $0.0475 \pm 0.114(n=6)$ and $0.0223 \pm 0.0491(n=5)$, respectively. There was no migration in the control group of ACC-2-pENegative, that is to say, there was no human gene in the lung tissue of nude mice, and the average migration rate was $\sim 0.0119 \pm 0.0251$. The nodules formed in the lung of ACC-2-Xb-19 and ACC-2-Xb-M were confirmed to be of the typical tumor tissue features of $\mathrm{ACC}$ by $\mathrm{H} \& \mathrm{E}$ staining (Fig. 5C, the third line), and it proved the XAGE-1b protein expression in the lung migration by IHC staining (Fig. 5C, the forth and fifth line).
Inhibition of proliferation in vitro and nude mouse subcutaneous tumors of ACC-M cells with interference of XAGE-1b expression. We detected RNA interfering effects on the exogenous expression of green fluorescence fusion protein by several candidate vectors. RNA interfering effects were observed through co-transfecting $293 \mathrm{~T}$ cells with pG-Sh-a, b, c and pEGFP-Xb-GFP vector, Lipofectamine 2000 group was regarded as the control without transfection, pG-Negative and pG-Positive vector interfering GFP groups were regarded as the positive and negative control group co-transfecting with pEGFP-XAGE-GFP vector. The results were observed through the fluorescence microscopy and photographed $36 \mathrm{~h}$ later (Fig. 6). When the interference with the targeting plasmid ratio is $4: 1$ and $10: 1$, the fluorescence intensity of pG-Sh-a group was observed to decrease greatly close to the positive control group level, pG-Sh-b group decreased evidently but no more than $\mathrm{pG}-\mathrm{Sh}$-a group and pG-Sh-c groups, the green fluorescence expression is the same as negative pG-Negative.

Interference on endogenous expression of XAGE-1b in SPC-A1 cells was studied in detail. Semi-quantitative RT-PCR 
A

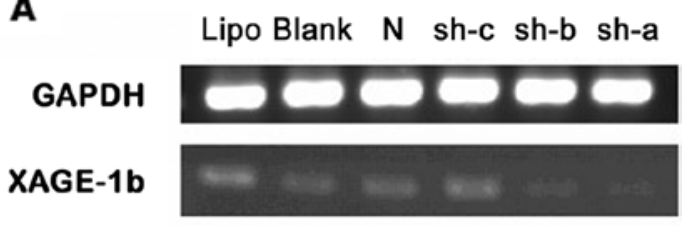

B

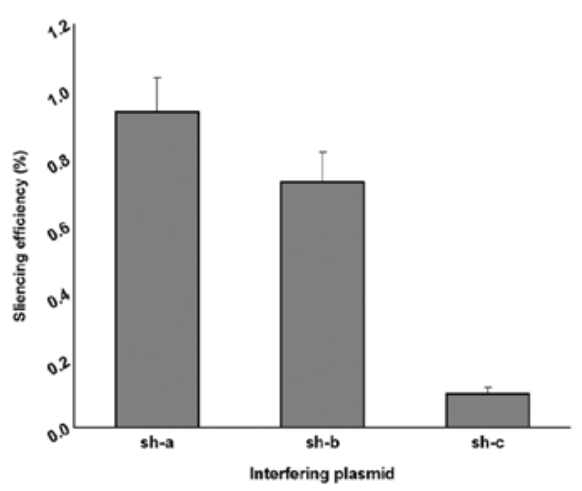

Figure 7. The endogenous interference efficacy of the shRNA expression vector against XAGE-1b. (A) The interfering effects were identified by semi-quantitative RT-PCR. Lipo group, the blank cell control group with Lipofectamine 2000 and no plasmid; Blank, empty vector control group; $\mathrm{N}$ group, negative interfering control; sh-a, sh-b, sh-c: the interfering vector on the different position of XAGE-1b. (B) The interference effects were identified by quantitative PCR and performed in triplicate.

was applied and we found that XAGE-1b expression transfected with the interfering vector sh-a, and sh-b decreased evidently and was less than the negative control, empty control and no-transfected vector group, and the interfering effects were not obvious in the sh-c group (Fig. 7A). For confirming the interference rate and selecting the best interfering vector, we quantitatively and calculated the interfering rate by real-time PCR method (Fig. 7B). The results showed that the interference rate of sh-a vector is the highest among three groups and reach $94 \%$, the others are $73.2 \%$ and $10 \%$ in the sh-b and sh-c group, respectively.

The pG-Sh-a vector was chosen to establish the stable interfering cell strains for the highest interference rate, the negative control group of plasmid pG-Negative was also screened. Because of the interfering plasmid with the red fluorescence protein and linearized operation before transfection, the expression of red fluorescence protein could be used for characterizing the integration of the transfected fragment and the successful expression of the interference sequence, and the cell clones with the bright red fluorescence protein were chosen as the stable interfering cell strains. There are two resistance cell clones with $100 \%$ expression of red fluorescence protein in each group respectively, and one was chosen as the ultimate stable cell strain named ACC-M-pGSh-a and ACC-M-pG-Negative to be used for the research on proliferation in vitro and in vivo of nude mice (Fig. 8A). The proliferation of ACC-M-pG-Sh-a cells was observed to be less than ACC-M-pG-Negative at the beginning of the second day and less than ACC-M at the beginning of the third day according to the MTT assay ( $\mathrm{p}<0.01$, Fig. $8 \mathrm{~B})$. In the cloning study, the amount of cell cloning of ACC-M-pG-Sh-a is less than ACC-M-pG-Negative and ACC-M group, and about 75\% of the control (Fig. 8C). The tumor volume in ACC-M-pG-Sh-a is less than ACC-M-pG-Negative and ACC-M group, and the growth began to slow at the beginning of the fifteenth day with the evident difference (Fig. 8D). The mouse weight in ACC-MpG-Sh-a is 4-8 times less than the ACC-M-pG-Negative and ACC-M groups (Fig. 8E) and the tumor volume is 7-11 times less than the control group (Fig. 8F).

The effects on the ability of subcutaneous tumors with XAGE-1b interference in vivo of nude mice was studied. Cells in different groups, including ACC-M-pG-Sh-a and ACC-MpG-Negative and ACC-M cell lines, were observed with the above method (Fig. 9A). The tumors were found to give off the bright red fluorescence under the exogenous excitation when two mice of ACC-M-pG-Negative group were observed with live fluorescence before the sacrifice on day 24 , it showed the method could be used for the quantitation of tumor volume and tracer of tumor cells (Fig. 9B). H\&E staining displayed the characteristics of ACC (Fig. 9C) and it confirmed the difference of XAGE-1b expression by IHC staining (Fig. 9D). The microvessel density of the tumors was also calculated. The microvessel density of ACC-M-pG-Sh-a is $12.375 \pm 3.94$, less than the value of $14.25 \pm 3.83$ in ACC-M-pG-Negative group without significant statistical difference (Fig. 9E and F).

\section{Discussion}

No clear role for XAGE-1b exists as yet in tumorigenesis of ACC. We found the negative effects on the proliferation phenotype of ACC-M cell lines in vivo and in vitro with XAGE-1b downregulation, and the results showed that XAGE-1b overexpression promoted the proliferation of ACC-2 cell lines in vivo and in vitro, and its overexpression promoted the transmembrane invasion in ACC-2 cell lines in vitro and the metastasis in vivo of nude mice. The proliferation in vitro of ACC-M cell lines and subcutaneous tumors of nude mice was inhibited by interference with XAGE-1b expression. The results also showed ACC- 2 cells with XAGE-1b overexpression presenting more rapid tumor growth and higher ability of transmembrane invasion in vivo and in vitro, and more angiogenesis. All the above results indicated that XAGE-1b promoted angiogenesis of tumor directly or indirectly, and it may lead to migration.

Some researchers have found close correlation between the microvessel density (MVD) of ACC and the expression of NF- $\mathrm{BB}, \mathrm{p} 65$, iNOS and VEGF, and correlation between the tumor stage, column, blood circulation transfer, relapse and the expression of the cell factor (22). The definite correlation research between XAGE-1b and ACC need to be done progressively. The tumor growth of ACC-M strain slowed with the stable interfering XAGE-1b in vivo and in vitro, its transmembrane ability also decreased in vitro. However, the lung metastases rate did not improve with XAGE-1b overexpression, it may be connected with low metastases in ACC-2 cell lines. Thus, it did not change the background of low metastases through changing gene expression, and the short time period following the inoculation after injection is another possible cause.

Angiogenesis is also crucial for the progression and metastasis of many types of human tumors. However, few studies have examined the implications of expression of angiogenesisrelated factors in salivary cancer. A recent study reported that 
A

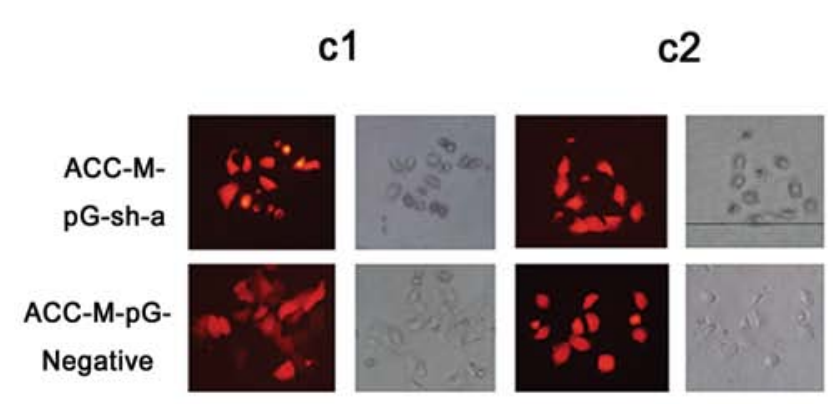

C

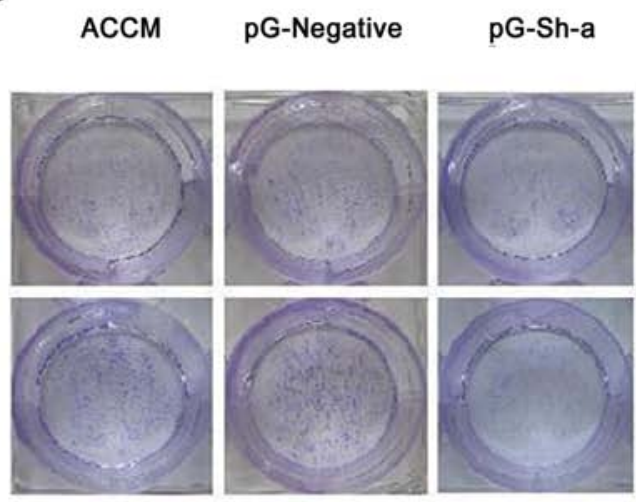

E

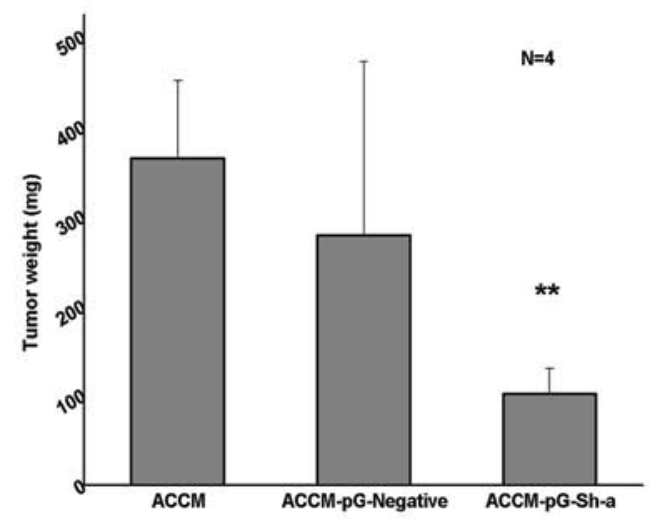

B

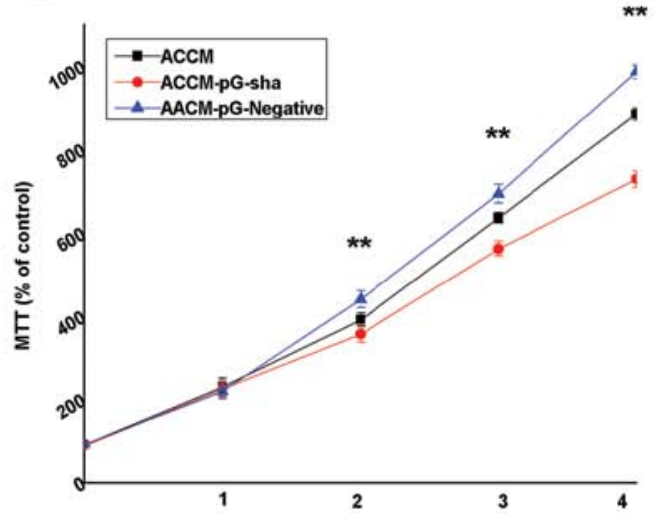

D

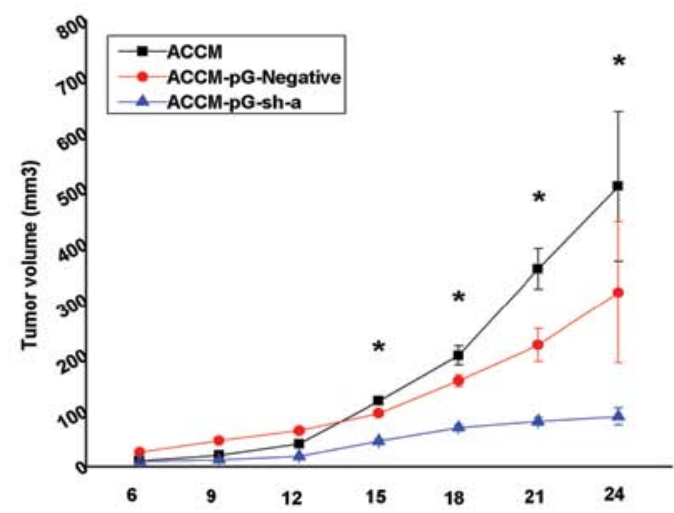

$\mathrm{F}$

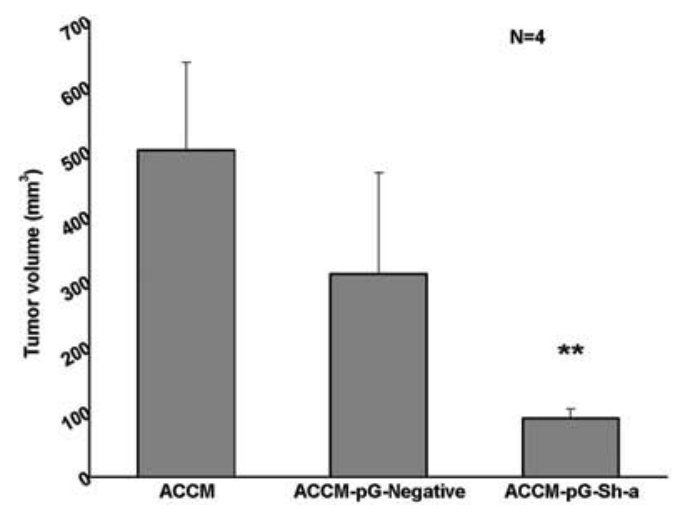

Figure 8. The effects on the proliferation of ACC-M cells in vitro and in the nude mice with XAGE-1b interference. (A) C1 and C2 representing the two resistant cell clones with $100 \%$ expression of red fluorescent protein, respectively, and as the final stable cells, named the ACC-M-pG-Sh-a and ACC-M-pGNegative. (B) The results of MTT and performed in triplicate with three repeat wells per time (**P<0.01). (C) The results of cloning. (D) The tumor growth curves and representing the significant difference between ACCM-pG-Sh-a and empty vector group ( $\mathrm{P}<0.05)$. (E) The comparison of tumor weight (mean \pm $\left.\mathrm{SD}, \mathrm{n}=3,{ }^{* *} \mathrm{P}<0.01\right)$. (F) The comparison of tumor volume (mean $\left.\pm \mathrm{SD}, \mathrm{n}=3,{ }^{* * *} \mathrm{P}<0.01\right)$.

both vascular endothelial growth factor (VEGF) and basic fibroblast growth factor are major angiogenesis factors in salivary gland tumors (8). In another study, loss of heterozygosity on chromosome 6q in ACC correlated with decreased expression of thrombospondin-2, which is a potent inhibitor of tumor angiogenesis (23). Furthermore, microvessel density which will be applied in our research is considered to be a prognostic indicator for the incidence of distant metastasis in salivary ACC. These findings suggest that the angiogenic signaling pathways of salivary ACC are potential therapeutic targets.

Salivary ACC cell line and its highly metastatic ACC clone were used as model systems to reveal the gene expression alteration related to metastasis mechanism. The correlation of metastatic phenotypic changes and expression levels of XAGE-1b gene was further validated by using RT-PCR analysis (24). A poorly metastatic ACC-2 cell line and highly metastatic ACC-M cell line were selected as an 
A

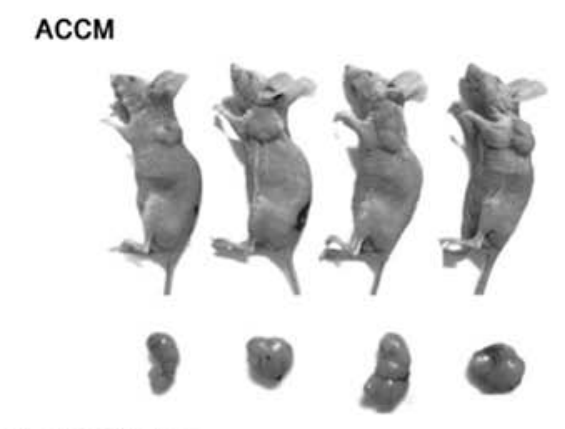

ACCM-pG-Sh-a

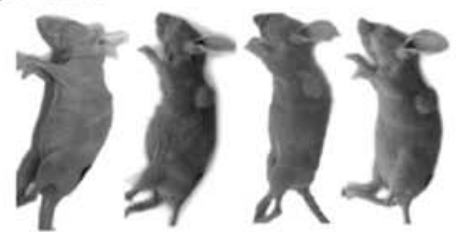

ACCM-pG-Negative

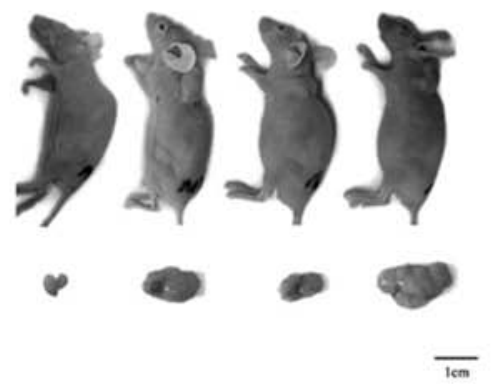

B

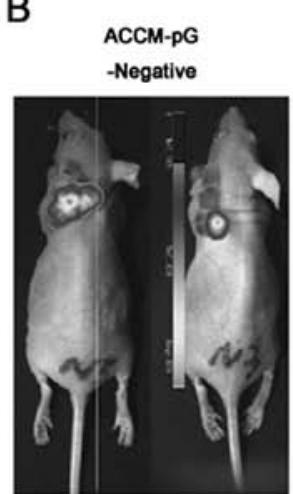

$\mathrm{E}$

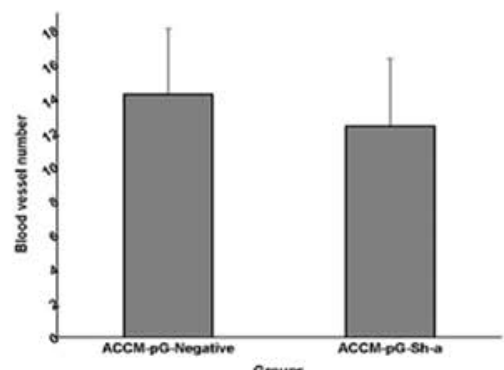

ACCM-pG-Sh-a
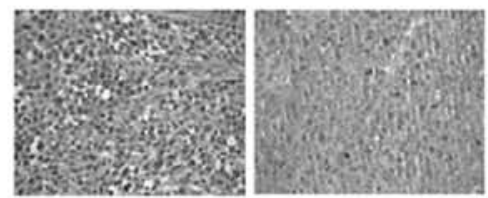

ACCM-pG-Negative

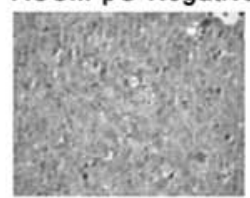

D

ACCM

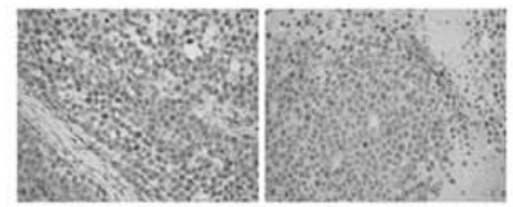

ACCM-pG

-Negative

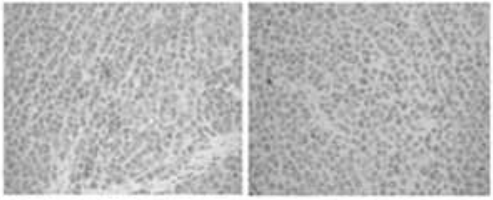

ACCM-pG

Sh-a

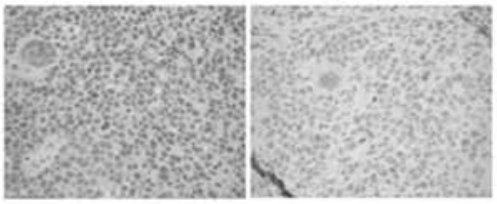

F ACCM-pG-Negative

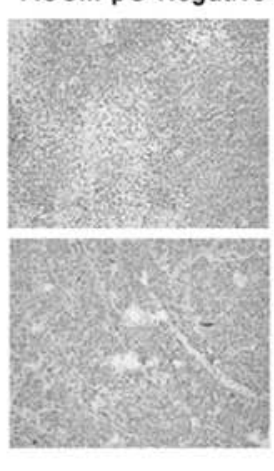

ACCMI-pG-Sh-a

Figure 9. The subcutaneous tumor of ACC in the nude mice with XAGE-1b interference. (A) The subcutaneous tumor in nude mice (n=4) and the scale bar characterizing the tumor size as $1 \mathrm{~cm}$ is in the right corner. (B) The imaging of live animals. (C) H\&E staining of the tumor tissues (x200). (D) IHC of XAGE-1b in tumor tissues. Left, normal staining control; right, negative control without primary antibody. (E) The comparison of the blood vessel number in tumor between ACCM-pG-Sh-a and ACCM-pG-Negative $(\mathrm{P}>0.05)$. (F) The typical tumor vascular staining of ACCM-pG-Sh-a and ACCM-pG-Negative group.

experimental model to study on metastatic mechanism procedures (25). A salivary ACC cell line ACC-2 and a highly metastatic salivary ACC clone ACC-M, which was screened from ACC-2 by the combination in vivo selection and cloning in vitro (26). Since ACC-2 and ACC-M share identical genetic background except for different metastatic behavior, it is presumed that the differentially expressed genes ACC-2 and ACC-M are metastasis related genes, which play direct or indirect roles in the progres- sion of metastasis. We constructed a different vector for expressing different levels of XAGE-1b and observed its effect on the proliferation and migration after transfected into ACC-2 and ACC-M cell lines. Particularly, cancer cell invasion and metastasis are the critical processes that define the aggressive phenotype of human cancers and pose major impediments to treatment $(27,28)$. Whereas the development of anticancer therapy is traditionally focused on the inhibition of cancer cell proliferation, therapeutic 
strategies targeted toward inhibiting the spread of cancer cells from a primary tumor to secondary sites can be inhibited.

The results on the tumorigenesis mechanism of ACC showed correlation between its tumorigenesis and the mutation of chromosome $6 \mathrm{q}, 9 \mathrm{q}$ and $17 \mathrm{p}$ on the genome level, but there is shortage of definite evidence (3). It was found that the differentiation to malignant development of ACC may be connected with the point mutation of p53 $(29,30)$. Interfering Skp2 can inhibit the proliferation of ACC with the p27 downregulation $(31,32)$. The overexpression of downstream factor Ebp1 in the ErbB signaling pathway of ACC-M strain can decrease the proliferation, anchorage and migration in vitro (34). A20 can decrease the invasiveness of ACC-M cells with downregulation of the expression of $\mathrm{NF}-\kappa \mathrm{B}$ (33). Data on the tumorigenesis mechanism of ACC are scarce and no report on its high metastases exists. Some research has shown higher expression frequency of C-kit protein in ACC, and it leads to lower treatment efficiency of ACC with imatinib (a kind of tyrosine kinase inhibitor) (34). Although HER2 overexpression in ACC has been suggested, is not evident in ACC with the HER2-target drug trastuzumab (35). It is important to study the mechanism of tumorigenesis and metastases of ACC.

We found that XAGE-1b is connected with the tumor growth and metastases in ACC through overexpression and interference as one of the CTAs in the study. The mechanism of action and the correlation with angiogenesis are worthy of research progressively in the future.

\section{Acknowledgements}

This study is sponsored by Chinese National Natural Science Foundation (no. 30772591).

\section{References}

1. Parkin DM, Laara E and Muir CS: Estimates of the worldwide frequency of sixteen major cancers in 1980. Int J Cancer 41: 184-197, 1988.

2. Stell PM: Survival time in end-stage head and neck cancer. Eur J Surg Oncol 15: 407-410, 1989.

3. Bockmühl U, Wolf G, Schmidt S, Schwendel A, Jahnke V, Dietel $\mathrm{M}$ and Petersen I: Genomic alterations associated with malignancy in head and neck cancer. Head Neck 20: 145-151, 1998.

4. Dodd RL and Slevin NJ: Salivary gland adenoid cystic carcinoma: a review of chemotherapy and molecular therapies. Oral Oncol 42: 759-769, 2006

5. Ampil FL and Misra RP: Factors influencing survival of patients with adenoid cystic carcinoma of the salivary glands. J Oral Maxillofac Surg 45: 1005-1010, 1987.

6. Spiro RH: Distant metastasis in adenoid cystic carcinoma of salivary origin. Am J Surg 174: 495-498, 1997.

7. Ito $\mathrm{H}$, Hatori $M$, Kinugasa $Y$, Irie $T$, Tachikawa $T$ and Nagumo M: Comparison of the expression profile of metastasis-associated genes between primary and circulating cancer cells in oral squamous cell carcinoma. Anticancer Res 23: 1425-1431, 2003.

8. Ishibashi H, ShiratuchiT, Nakagawa K, Onimaru M, Sugiura T and Sueishi K: Hypoxiainduced angiogenesis of cultured human salivary gland carcinoma cells enhances vascular endothelial growth factor production and basic fibroblast growth factor release. Oral Oncol 37: 77-83, 2001.

9. Simpson AJ, Caballero OL, Jungbluth A, Chen YT and Old LJ: Cancer/testis antigens, gametogenesis and cancer. Nat Rev Cancer 5: 615-625, 2005.

10. Scanlan MJ, Simpson AJ and Old LJ: The cancer/testis genes: review, standardization, and commentary. Cancer Immun 4: 1 , 2004.
11. Old LJ: Cancer/testis (CT) antigens - a new link between gametogenesis and cancer. Cancer Immun 1: 1, 2001.

12. Davis ID, Chen W, Jackson H, Parente P, Shackleton M, Hopkins W, Chen Q, Dimopoulos N, Luke T, Murphy R, Scott AM, Maraskovsky E, McArthur G, MacGregor D, Sturrock S, Tai TY, Green S, Cuthbertson A, Maher D, Miloradovic L, Mitchell SV, Ritter G, Jungbluth AA, Chen YT, Gnjatic S, Hoffman EW, Old LJ and Cebon JS: Recombinant NY-ESO-1 protein with ISCOMATRIX adjuvant induces broad integrated antibody and CD4(+) and CD8(+) T cell responses in humans. Proc Natl Acad Sci USA 101: 10697-10702, 2004.

13. Zhang Y, Sun Z, Nicolay H, Meyer RG, Renkvist N, Stroobant V, Corthals J, Carrasco J, Eggermont AM, Marchand M, Thielemans K, Wölfel T, Boon T and van der Bruggen P: Monitoring of anti-vaccine CD4 T cell frequencies in melanoma patients vaccinated with a MAGE-3 protein. J Immunol 174: 2404-2411, 2005.

14. Nakagawa K, Noguchi Y, Uenaka A, Sato S, Okumura H, Tanaka M, Shimono M, Ali Eldib AM, Ono T, Ohara N, Yoshino T, Yamashita K, Tsunoda T, Aoe M, Shimizu N and Nakayama E: XAGE-1 expression in non-small cell lung cancer and antibody response in patients. Clin Cancer Res 11: 5496-5503, 2005.

15. Gure AO, Chua R, Williamson B, Gonen M, Ferrera CA, Gnjatic S, Ritter G, Simpson AJ, Chen YT, Old LJ and Altorki NK: Cancertestis genes are coordinately expressed and are markers of poor outcome in nonsmall cell lung cancer. Clin Cancer Res 11: 8055-8062, 2005.

16. Brinkmann U, Vasmatzis G, Lee B and Pastan I: Novel genes in the PAGE and GAGE family of tumor antigens found by homology walking in the dbEST database. Cancer Res 59: 1445-1448, 1999.

17. Liu XF, Helman LJ, Yeung C, Bera TK, Lee B and Pastan I: XAGE-1, a new gene that is frequently expressed in Ewing's sarcoma. Cancer Res 60: 4752-4755, 2000.

18. Zendman AJ, Van Kraats AA, Weidle UH, Ruiter DJ and Van Muijen GN: The XAGE family of cancer/testis-associated genes: alignment and expression profile in normal tissues, melanoma lesions and Ewing's sarcoma. Int J Cancer 99: 361-369, 2002.

19. Egland KA, Kumar V, Duray P and Pastan I: Characterization of overlapping XAGE-1 transcripts encoding a cancer testis antigen expressed in lung, breast, and other types of cancers. Mol Cancer Ther 1: 441-450, 2002.

20. Ali Eldib AM, Ono T, Shimono M, Kaneko M, Nakagawa K, Tanaka R, Noguchi Y and Nakayama E: Immunoscreening of a cDNA library from a lung cancer cell line using autologous patient serum: identification of XAGE-1b as a dominant antigen and its immunogenicity in lung adenocarcinoma. Int $\mathrm{J}$ Cancer 108: 558-563, 2004.

21. Sato S, Noguchi Y, Ohara N,Uenaka A, Shimono M, Nakagawa K, Koizumi F, Ishida T, Yoshino T, Shiratori Y and Nakayama E: Identification of XAGE-1 isoforms: predominant expression of XAGE-1b in testis and tumors. Cancer Immun 7: 5-13, 2007.

22. Scanlan MJ, Gure AO, Jungbluth AA, Old LJ and Chen YT: Cancer/testis antigens: an expanding family of targets for cancer immunotherapy. Immunol Rev 188: 22-32, 2002.

23. Kishi M, Nakamura M, Nishimine M, Ishida E, Shimada K, Kirita $\mathrm{T}$ and Konishi N: Loss of heterozygosity on chromosome $6 \mathrm{q}$ correlates with decreased thrombospondin-2 expression in human salivary gland carcinomas. Cancer Sci 94: 530-535, 2003.

24. Huang D, Chen W, He R, Yu F, Zhang Z and Qiu W: Different cDNA microarray patterns of gene expression reflecting changes during metastatic progression in adenoid cystic carcinoma. World J Surg Oncol 1: 28, 2003.

25. An J, Sun JY, Yuan Q, Tian HY, Qiu WL, Guo W and Zhao FK: Proteomics analysis of differentially expressed metastasisassociated proteins in adenoid cystic carcinoma cell lines of human salivary gland. Oral Oncol 40: 400-408, 2004.

26. Guan XF, Qiu WL, He RG and Zhou XJ: Selection of adenoid cystic carcinoma cell clone highly metastatic to the lung: an experimental study. Int J Oral Maxillofac Surg 26: 116-119, 1997.

27. Patel KJ, Pambuccian SE, Ondrey FG, Adams GL and Gaffney PM: Genes associated with early development, apoptosis and cell cycle regulation define a gene expression profile of adenoid cystic carcinoma. Oral Oncol 42: 994-1004, 2006.

28. Chen W, Zhang HL, Shao XJ, Jiang YG, Zhao XG, Gao X, Li JH, Yang J, Zhang YF, Liu BL and Sun MY: Gene expression profile of salivary adenoid cystic carcinoma associated with perineural invasion. Tohoku J Exp Med 212: 319-334, 2007. 
29. Chau Y, Hongyo T, Aozasa K and Chan JKC: Dedifferentiation of adenoid cystic carcinoma: a report of a case implicating p53 gene mutation. Hum Pathol 32: 1403-1407, 2001.

30. Karja VJ, Syrjanen KJ, Kurvinen AK and Syrjanen SM Expressions and mutations of p53 in salivary gland tumours. J Oral Pathol Med 26: 217-223, 1997.

31. Keikhaee MR, Kudo Y, Siriwardena S, Wu L, Ogawa I and Takata T: Skp2 expression is associated with down-regulation of $\mathrm{p} 27$ protein and cell proliferation in salivary adenoid cystic carcinoma. Virchows Arch 450: 567-574, 2007.

32. Yu Y, Chen W, Zhang Y, Hamburger AW, Pan H and Zhang Z: Suppression of salivary adenoid cystic carcinoma growth and metastasis by ErbB3 binding protein Ebp1 gene transfer. Int J Cancer 120: 1909-1913, 2007.
33. Zhang B, Guan CC, Chen WT, Zhang P, Yan M, Shi JH, Qin CL and Yang Q: A20 inhibits human salivary adenoid cystic carcinoma cells invasion via blocking nuclear factor-kappaB activation. Chin Med J 120: 1830-1835, 2007.

34. Freier K, Flechtenmacher C, Walch A, Devens F, Mühling J, Lichter P, Joos S and Hofele C: Differential KIT expression in histological subtypes of adenoid cystic carcinoma (ACC) of the salivary gland. Oral Oncol 41: 934-939, 2005.

35. Dori S, Vered M, David R and Buchner A: HER2/neu expression in adenoid cystic carcinoma of salivary gland origin: an immunohistochemical study. J Oral Pathol Med 31: 463-467, 2002. 